\title{
Research
}

\section{Developing research priorities in Australian primary health care: a focus on nutrition and physical activity}

Lauren Ball $^{\mathrm{A}, \mathrm{E}}$, Katelyn Barnes ${ }^{\mathrm{A}}$, Michael Leveritt ${ }^{\mathrm{B}}$, Lana Mitchell ${ }^{\mathrm{A}}$, Lauren T Williams ${ }^{\mathrm{A}}$, Dianne Ball $^{\mathrm{C}}$ and Elizabeth Patterson ${ }^{\mathrm{D}}$

${ }^{A}$ Centre for Health Practice Innovation, Menzies Health Institute Queensland, Griffith University, Gold Coast, Qld 4222, Australia.

${ }^{B}$ School of Human Movement and Nutrition Sciences, The University of Queensland, Brisbane, Qld 4072, Australia.

${ }^{\mathrm{C}}$ Communio Pty Ltd, North Sydney, NSW 2060, Australia.

${ }^{\mathrm{D}}$ Faculty of Medicine, Dentistry and Health Sciences, The University of Melbourne, Melbourne, Vic. 3000, Australia.

${ }^{\mathrm{E}}$ Corresponding author. Email: 1.ball@griffith.edu.au

Research priority setting is an important component of research planning, particularly when research options exceed available resources. This study identified the research priorities for supporting healthy lifestyle behaviours in the Australian primary healthcare setting. A five-step stakeholder engagement process was undertaken. Ten stakeholder organisations participated in the process, including patient representatives, health professional associations, health educators, researchers, government advisors and policymakers. Each organisation was asked to provide up to three research questions deemed as a priority. Research questions were critically appraised by the project team for answerability, sustainability, effectiveness, potential for translation and potential to affect disease burden. A blinded scoring system was used to rank the appraised questions, with higher scores indicating higher priority (range of scores possible 87-156). Thirteen unique research questions were submitted by stakeholders and achieved a range of scores from 87 to 139 points. The highest scoring research questions focused on: (i) the effectiveness of different health professionals at facilitating healthy lifestyle behaviours; (ii) the effect of health literacy on behaviour change; and (iii) cost-benefit analysis of healthy lifestyle promotion in primary health care. These priorities can be used to ensure future research projects directly align with the needs and preferences of research end-users.

\section{What is known about the topic?}

- The priorities for research regarding how to best support patients through Australian primary healthcare services to have healthy dietary and physical activity behaviours are presently unknown.

\section{What does this paper add?}

- This paper outlines priority research questions for primary healthcare, such as the effectiveness of different health professionals at facilitating healthy behaviours and the effect of health literacy on behaviour change. 
L. Ball et al.

Research priorities in Australian primary health care

Additional keywords: chronic disease, general practice, intervention studies, nutritional management, nutrition therapy, primary care, research methods.

\section{Introduction}

The prevention and management of chronic disease is recognised as a major global health challenge (World Health Organization 2003; Lim et al. 2012). Poor dietary behaviours and physical inactivity accelerate the progression of many chronic diseases and are estimated to contribute more than $10 \%$ of the global burden of disease (World Health Organization 2003; Lim et al. 2012). Despite the existence of evidence-based guidelines for healthy eating and physical activity (National Health and Medical Research Council 2013), it is estimated that nearly all (94\%) Australian adults have dietary behaviours that do not align with the guidelines (Australian Institute of Health and Welfare 2012), and that less than 50\% are sufficiently physically active (Australian Bureau of Statistics 2012). Given these population statistics, the promotion of healthy dietary behaviours and physical activity is a priority for health services, including primary health care (Halcomb et al. 2007). Promoting healthy dietary behaviours and physical activity is a key component of best-practice guidelines for primary health professionals (Diabetes Australia and Royal Australian College of General Practitioners 2008; Royal Australian College of General Practitioners 2015).

Numerous approaches to support patients to have healthy dietary behaviours and engage in physical activity have been tested in Australia (Australian Institute for Primary Care 2008). Previous research has identified that primary health professionals, specifically General Practitioners and Dietitians, are regarded as trusted and reliable sources of nutrition information (Ball et al. 2014). However, barriers within the current model of primary health care, such as time and funding, limit the capacity of these primary care providers to effectively shift population dietary behaviours and physical activity levels (Foster et al. 2009; Volker et al. 2015). Practise Nurses are increasingly recognised as health professionals ideally placed to enhance healthy dietary behaviours and physical activity in primary care (Sargent et al. 2012). However, these primary health professionals have been shown to elicit only modest improvements in patients' dietary and physical activity behaviours, with no clear factors moderating the effectiveness of interventions (Ball et al. 2015). There is a limited body of research that can confirm the ideal approach to implement in primary healthcare practice, signalling that further work in this area is required (Ball et al. 2015). Given concerns over research wastage in Australia (Herbert et al. 2013), an evidence-based approach to ensure that research is efficient, targeted and prioritised is of paramount importance.

Research priority setting is a key component of research planning, particularly when research options far exceed available resources (Rudan et al. 2008). The objective of research priority setting is 
to use a fair, transparent and systematic approach to identify the most important research projects to conduct (Rudan et al. 2008). Research prioritisation is a valuable strategy used to ensure that future research projects are directly aligned with the needs and preferences of research end-users (Rudan et al. 2008). This is important because it increases the likelihood that research projects elicit a meaningful effect and can be implemented in a sustainable, feasible and acceptable manner (UK Medical Research Council et al. 2015). Research priorities have been developed for specific aspects of nutrition research, such as micronutrient intake for child health (Brown et al. 2009) and enteral feeding in hospitals (Weenen et al. 2014). This process has not yet been applied to other contexts, such as interventions in primary health care that support patients to have healthy dietary behaviours and increased levels of physical activity.

The aim of this study was to identify research priorities for supporting healthy lifestyle behaviours in the Australian primary healthcare setting. The findings are essential for targeting future Australian research and will inform future research projects to meet the needs of research end-users in a transparent manner.

\section{Methods}

Overview

A five-step stakeholder engagement process was undertaken to set priorities for research on healthy dietary and physical activity behaviours in Australian primary health care. An overview of the stakeholder engagement process is shown in Fig. 1. The stakeholder engagement process was informed by guidelines for setting research priorities (Rudan et al. 2008; Yoshida 2016). The study was approved by the relevant institutional Human Research Ethics Committee (reference number 2015/900).

\section{Step 1: select management team}

The project utilised a management team to provide informed input throughout the stakeholder engagement process. The management team was formed in October 2015 through professional contacts of the researchers and comprised seven members. All members of the management team had PhDs, were health professionals (including dietitians, exercise scientists and nurses) and had extensive experience in primary healthcare research, including obtaining research funding support, developing research proposals, conducting studies and disseminating findings. The size of the management team was deemed as sufficiently large to facilitate comprehensive input on the project, while still small enough to facilitate practical and timely discussions over the course of the project.

\section{Step 2: confirm scope and context}

The research scope and context was drafted and confirmed by the management team through iterative written and verbal discussions until consensus was achieved. The discussions confirmed the 
population of interest, health conditions of interest, goals for research translation and relevant stakeholders. An explanation of the research scope and context was developed in preparation to distribute to stakeholders, and read as follows:

The research we are focusing on examines the best way to support patients in primary health care to have healthy dietary and physical activity behaviours. The support could be provided by health professionals including General Practitioners, Practice Nurses, Dietitians, Nutritionists, Exercise Physiologists, Physiotherapists, or Diabetes Educators. The research should focus on healthy lifestyle behaviours to prevent and manage chronic disease, and should not focus on acute conditions such as dietary allergies or musculoskeletal injuries. Outcomes could be measured by: quality of life, dietary intake, physical activity time/intensity, serum bio-markers of disease risk, serum bio-markers of healthfulness, weight, waist circumference, Body Mass Index, and/or knowledge or awareness of diet and physical activity guidelines. [Project Management Team]

\section{Step 3: engage with stakeholders}

Categories of potential stakeholders were identified by the management team to include medical practitioner bodies, nursing organisations, nutrition and dietetic organisations, physical activity associations, government and non-government agencies, primary health networks, health insurance providers and research bodies. A list of stakeholder contact details was developed using publicly available information from websites. Preference was given to nationally representative bodies in order to capture informed opinions from the broadest possible audience. A total of 27 stakeholder organisations with an interest in primary health care were approached by emailing the director, president or external relations officer to explain the aim and ethical approval of the project. In addition, the email outlined the scope and context of the research and asked representatives to provide up to three research questions deemed as a priority via an online survey portal. The organisations included Australian medical practitioner bodies ( $n=4)$, nursing organisations ( $n=2)$, pharmacy organisations ( $n=1)$, nutrition and dietetic organisations $(n=3)$, physical activity associations $(n=$ 3 ), government agencies ( $n=2)$, non-government agencies $(n=5)$, primary health network associations $(n=1)$, patient advocacy associations $(n=2)$, health insurance advisors $(n=2)$ and research bodies $(n=4)$. Owing to the anonymous nature of the online survey portal, it was not possible to identify which of these 27 organisations provided input and which declined.

\section{Step 4: confirm criteria for appraising and prioritising research}

The criteria for appraising research questions were drafted and confirmed by the management team through blinded ranking. Fifteen possible criteria and their explanations were proposed and ranked in order of relevance and importance for the scope and context of research (Rudan et al. 2008). The four highest ranked criteria (answerability, sustainability, effectiveness and potential for translation and 
effect on disease burden) were used in scoring each research option proposed by the stakeholders. Between two and four assessment questions were drafted and confirmed by the management team to adequately assess each criterion. Box 1 outlines the criteria and assessment questions applied when appraising each research question.

\section{Step 5: score research questions}

The research questions submitted by stakeholders were initially reviewed for alignment with scope and ability to be scored using the criteria and assessment questions. Questions that significantly overlapped with each other were collapsed and minor edits were made to the wording of some research questions to enable structured scoring by the management team.

The submitted research questions were scored independently by each member of the management team using the assessment questions for each criteria listed in Box 1. Each assessment question was scored via an online survey portal based on the answers provided by each member of the management team, as either: 'Yes' (3 points), 'Unsure' (2 points) or 'No' (1 point). The total number of points awarded to each research question was summed by one investigator (LB) and confirmed by a second (KB) in order to provide an overall score for each criterion, which ranged from 52 to 156, given the assessment criteria and size of the management team. Finally, the appraised questions were ranked from highest to lowest score by one investigator (LB) and confirmed by a second (KB) to provide a list of prioritised research questions.

\section{Results}

Fifteen research questions from 10 stakeholder bodies were obtained from the stakeholder engagement process. Owing to the anonymous nature of the online survey portal, it was not possible to identify which stakeholder bodies submitted research questions. Two questions on weight management and two on effectiveness of nutrition care were collapsed with others because of considerable overlap, resulting in 13 unique research questions for appraisal. Table 1 outlines the research questions submitted as well as the score achieved for each criterion. The questions ranged from 87 to 139 points.

The scored questions resulted in a clear delineation of questions, with only two achieving the same overall score. The highest scoring question assessed the effectiveness of community pharmacists at facilitating improved dietary behaviours and physical levels of patients. Other high-scoring questions focused on measuring the effectiveness of different health professionals at facilitating healthy lifestyle behaviours; the effect of health literacy on behaviour change; and cost-benefit analysis of healthy lifestyle promotion in primary health care.

The ranking of questions differed for each of the four criteria. For example, the second highest scoring question in terms of answerability (effectiveness of walk-to-school groups) was only ninth 
highest for the sustainability criterion, third highest for the effectiveness criterion and 11th highest for the potential for translation criterion.

\section{Discussion}

This study is the first to identify the research priorities for supporting healthy lifestyle behaviours in the Australian primary healthcare setting. The process for developing these priorities was consultative and consensus-based. The stakeholder engagement process resulted in a wide variety of research questions being critically appraised and prioritised. This suggests that the aim of developing a fair, transparent and systematic approach to identifying the most important research priorities was satisfied (Rudan et al. 2008). This work can inform future research projects that align with the needs and preferences of research end-users in Australia.

The highest scoring research questions focused on the effectiveness of different health professionals at facilitating healthy lifestyle behaviours (specifically pharmacists); the effect of health literacy on behaviour change; and cost-benefit analysis of healthy lifestyle promotion in primary health care. Interestingly, most of these topics (aside from cost-benefit analyses) are being actively researched in Australia at the present time (Ball et al. 2013; Faruqi et al. 2014; Ball et al. 2015;

Maher et al. 2015). This indicates that current research activities are generally aligning with the needs and preferences of research end-users. The extent to which current research projects align with the prioritised research questions when planning projects should be reviewed, with particular emphasis on incorporating health economics into project design. Furthermore, there is scope to advance on existing projects to focus on intervention research, using implementation science to translate findings into practice. Funding bodies and health service providers are encouraged to use this information in decision-making about future projects.

The ranking of research questions differed for each criterion. This suggests that a different list of priority research questions may have been produced using different criteria. An iterative approach was used in the present study to determine the most appropriate criteria for appraising the research questions. These criteria could be used to strengthen potential research questions by enhancing answerability, or altering study designs to increase the potential for translation to practice. Providing stakeholder organisations with instructions on the optimal development of research questions may help align future submissions to the criteria.

The attributes of the submitted research questions require consideration before future research. For example, the submitted research questions differed in scope and focus, and appeared to represent the specific advocacy goals of stakeholders rather than the broader goal of enhanced primary healthcare services. Many of the stakeholders represented the interests of health professionals, with less emphasis on patients or consumers. Furthermore, the research questions that were more specifically worded (i.e. incorporating clear outcome measures) appeared to achieve higher scores than generally 
worded questions. This suggests that the appraisal by the management team may have been more favourable when the questions were easily understood and clearly described, rather than whether the question was an important priority. These limitations suggest that future research planning should use the prioritised research questions as a source of guidance, while also considering other relevant factors such as existing projects and national priorities in primary health care. Other techniques to elicit consensus such as Delphi approaches may also be helpful to facilitate iterative feedback from stakeholder organisations.

In conclusion, this study has identified the research priorities for supporting healthy lifestyle behaviours in the Australian primary healthcare setting. The process used provides a consultative, consensus-based model that could be applied elsewhere. The stakeholder engagement process resulted in a wide variety of research questions being critically appraised and prioritised. As a result, future research projects that align with the prioritised research questions are likely to meet the needs and preferences of research end-users in Australia.

\section{Conflicts of interest}

None declared.

\section{Acknowledgements}

The authors thank the stakeholder organisations for providing their input to the project.

\section{References}

$<$ eref $>$ Australian Bureau of Statistics (2012) Australian health survey. Available at

http://www.abs.gov.au/australianhealthsurvey [Verified 1 December 2014]</eref>

$<$ bok>Australian Institute for Primary Care (2008) System reform and development for chronic disease management. La Trobe University, Melbourne. $</$ bok $>$

$<$ bok>Australian Institute of Health and Welfare (2012) 'Risk Factors Contributing to Chronic Disease.'

(Australian Government: Canberra)</bok>

$<$ jrn>Ball L, Johnson C, Desbrow B, Leveritt M (2013) General practitioners can offer effective nutrition care to patients with lifestyle related chronic disease: a systematic review. Journal of Primary Health Care 5, 59-

69. $<$ jjn $>$

$<$ jrn>Ball L, Desbrow B, Leveritt M (2014) An exploration of individuals’ preferences for nutrition care from Australian primary care health professionals. Australian Journal of Primary Health 20, 113-120. doi:10.1071/PY12127</jrn>

$<$ jrn>Ball L, Leveritt M, Cass S, Chaboyer W (2015) Effect of nutrition care provided by primary health professionals on adults’ dietary behaviours: a systematic review. Family Practice 32, 605-617.</jrn>

<jrn>Brown KH, Hess SY, Boy E, Gibson RS, Horton S, Osendarp SJ, Sempertegui F, Shrimpton R, Rudan I

(2009) Setting priorities for zinc-related health research to reduce children's disease burden worldwide: an 
application of the Child Health and Nutrition Research Initiative's research priority-setting method. Public Health Nutrition 12, 389-396.</jrn>

$<$ bok>Diabetes Australia and Royal Australian College of General Practitioners (2008) 'Diabetes Management in General Practice', 14th edn. (Publisher: Sydney) </bok>

$<$ jrn>Faruqi N, Lloyd J, Ahmad R, Yeong LL, Harris M (2015) Feasibility of an intervention to enhance preventive care for people with low health literacy in primary health care. Australian Journal of Primary Health 21, 321-326. doi:10.1071/PY14061</jrn>

$<$ jrn>Foster M, Cornwell P, Fleming J, Mitchell G, Tweedy S, Hart A, Haines T (2009) Better than nothing? Restrictions and realities of enhanced primary care for allied health practitioners. Australian Journal of Primary Health 15, 326-334. doi:10.1071/PY08065</jrn>

$<$ jrn>Halcomb EJ, Davidson PM, Yallop J, Griffiths R, Daly J (2007) Strategic directions for developing the Australian general practice nurse role in cardiovascular disease management. Contemporary Nurse 26, 125135. doi:10.5172/conu.2007.26.1.125</jrn>

<jrn>Herbert D, Barnett A, Graves N (2013) Funding: Australia’s grant system wastes time. Nature 495, 314. doi:10.1038/495314d </jrn>

$<$ jrn>Lim SS, Vos T, Flaxman AD, Danaei G, Shibuya K, Adair-Rohani H, AlMazroa MA, Amann M, Anderson HR, Andrews KG, Aryee M, Atkinson C, Bacchus LJ, Bahalim AN, Balakrishnan K, Balmes J, Barker-Collo S, Baxter A, Bell ML, Blore JD, Blyth F, Bonner C, Borges G, Bourne R, Boussinesq M, Brauer M, Brooks P, Bruce NG, Brunekreef B, Bryan-Hancock C, Bucello C, Buchbinder R, Bull F, Burnett RT, Byers TE, Calabria B, Carapetis J, Carnahan E, Chafe Z, Charlson F, Chen H, Chen JS, Cheng AT-A, Child JC, Cohen A, Colson KE, Cowie BC, Darby S, Darling S, Davis A, Degenhardt L, Dentener F, Des Jarlais DC, Devries K, Dherani M, Ding EL, Dorsey ER, Driscoll T, Edmond K, Ali SE, Engell RE, Erwin PJ, Fahimi S, Falder G, Farzadfar F, Ferrari A, Finucane MM, Flaxman S, Fowkes FGR, Freedman G, Freeman MK, Gakidou E, Ghosh S, Giovannucci E, Gmel G, Graham K, Grainger R, Grant B, Gunnell D, Gutierrez HR, Hall W, Hoek HW, Hogan A, Hosgood HD III, Hoy D, Hu H, Hubbell BJ, Hutchings SJ, Ibeanusi SE, Jacklyn GL, Jasrasaria R, Jonas JB, Kan H, Kanis JA, Kassebaum N, Kawakami N, Khang Y-H, Khatibzadeh S, Khoo J-P, Kok C, Laden F, Lalloo R, Lan Q, Lathlean T, Leasher JL, Leigh J, Li Y, Lin JK, Lipshultz SE, London S, Lozano R, Lu Y, Mak J, Malekzadeh R, Mallinger L, Marcenes W, March L, Marks R, Martin R, McGale P, McGrath J, Mehta S, Memish ZA, Mensah GA, Merriman TR, Micha R, Michaud C, Mishra V, Hanafiah KM, Mokdad AA, Morawska L, Mozaffarian D, Murphy T, Naghavi M, Neal B, Nelson PK, Nolla JM, Norman R, Olives C, Omer SB, Orchard J, Osborne R, Ostro B, Page A, Pandey KD, Parry CDH, Passmore E, Patra J, Pearce N, Pelizzari PM, Petzold M, Phillips MR, Pope D, Pope CA III, Powles J, Rao M, Razavi H, Rehfuess EA, Rehm JT, Ritz B, Rivara FP, Roberts T, Robinson C, Rodriguez-Portales JA, Romieu I, Room R, Rosenfeld LC, Roy A, Rushton L, Salomon JA, Sampson U, Sanchez-Riera L, Sanman E, Sapkota A, Seedat S, Shi P, Shield K, Shivakoti R, Singh GM, Sleet DA, Smith E, Smith KR, Stapelberg NJC, Steenland K, Stöckl H, Stovner LJ, Straif K, Straney L, Thurston GD, Tran JH, Van Dingenen R, van Donkelaar A, Veerman JL, Vijayakumar L, Weintraub R, Weissman MM, White RA, Whiteford H, Wiersma ST, Wilkinson JD, Williams HC, Williams W, Wilson N, Woolf AD, Yip P, Zielinski 
JM, Lopez AD, Murray CJL, Ezzati M (2012) A comparative risk assessment of burden of disease and injury attributable to 67 risk factors and risk factor clusters in 21 regions, 1990-2010: a systematic analysis for the Global Burden of Disease Study 2010. Lancet 380, 2224-2260. doi:10.1016/S0140-6736(12)61766-8</jrn>

$<$ jrn>Maher JH, Lowe J, Hughes R (2015) Community pharmacy as a setting for public health nutrition action: Australian nutritionists’ perspectives. Public Health Nutrition 18, 1864-1872. doi:10.1017/S1368980014002201</jrn>

$<$ bok>National Health and Medical Research Council (2013) 'Australian Dietary Guidelines.' (Publisher: Canberra) $</$ bok $>$

$<$ bok>Royal Australian College of General Practitioners (2015) Smoking, Nutrition, Alcohol and Physical Activity (SNAP): A population health guide to behavioural risk factors in general practice. 2nd edn. (RACGP: Melbourne)</bok>

$<$ jrn>Rudan I, Gibson JL, Ameratunga S, El Arifeen S, Bhutta ZA, Black M, Black RE, Brown KH, Campbell H, Carneiro I, Chan KY, Chandramohan D, Chopra M, Cousens S, Darmstadt GL, Meeks Gardner J, Hess SY, Hyder AA, Kapiriri L, Kosek M, Lanata CF, Lansang MA, Lawn J, Tomlinson M, Tsai AC, Webster J, Child H, Nutrition Research Initiative (2008) Setting priorities in global child health research investments: guidelines for implementation of CHNRI method. Croatian Medical Journal 49, 720-733. doi:10.3325/cmj.2008.49.720</jrn>

$<$ jrn>Sargent GM, Forrest LE, Parker RM (2012) Nurse delivered lifestyle interventions in primary health care to treat chronic disease risk factors associated with obesity: a systematic review. Obesity Reviews 13, 1148 1171. doi:10.1111/j.1467-789X.2012.01029.x</jrn>

<jrn> UK Medical Research Council, Moore G, Audrey S, Barker M, Bond L, Bonell C, Hardeman W, Moore L, O’Cathain A, Tinati T, Wight D, Baird J (2015) Guidance on process evaluation of complex interventions. British Medical Journal. doi:10.1136/bmj.h1258</jrn>

$<$ jrn>Volker N, Williams LT, Davey RC, Cochrane T (2015) Community-based lifestyle modification workforce: an underutilised asset for cardiovascular disease prevention. Australian Journal of Primary Health 21, xx- $\mathrm{xx} .<$ jirn>

$<$ jrn>Weenen TC, Jentink A, Pronker ES, Commandeur HR, Claassen E, Boirie Y, Singer P (2014) Patient needs and research priorities in the enteral nutrition market - a quantitative prioritization analysis. Clinical Nutrition (Edinburgh, Lothian) 33, 793-801. doi:10.1016/j.clnu.2013.11.002</jrn>

$<$ bok> World Health Organization (2003) WHO Technical Report Series: diet, nutrition, and the prevention of chronic diseases. WHO, Geneva. $</$ bok $>$

$<$ jrn>Y Yoshida S (2016) Approaches, tools and methods used for setting priorities in health research in the 21(st) century. Journal of Global Health 6, 010507.</jrn> 


\section{Box 1. Criteria and assessment items used to appraise each research question}

All questions were answered in the format: 'yes' (3 points), 'unsure' (2 points) or 'no' (1 point).

\section{Criterion 1: answerability}

1.1. Is the research question clear, including well-defined study outcomes?

1.2. Can a study be feasibly designed to answer the research question?

1.3. Do you think that a study needed to answer the research question would feasibly obtain ethical approval?

1.4. Taking into account the level of difficulty to answer the questions (e.g. required design, safety, infrastructure, need to modify health professional behaviours), do you believe the research question can be answered in the current local, national or global context?

\section{Criterion 2: sustainability}

2.1. Taking into account the resources required to answer the research question, do you think the benefits from the research would be long lasting (i.e. $>5$ years)?

2.2. Do you think that the research question would be relevant and well justified for governmental, industry or nationally competitive funding?

\section{Criterion 3: effectiveness}

3.1. Do you believe the research could provide rationale to inform a future intervention, OR, do you believe there is enough rational to support the development of an intervention to answer the research question?

3.2. Do you believe an intervention that answers the research question will have equitable outcomes for all population groups?

3.3. Do you believe an intervention that answers the research question could be cost-effective?

\section{Criterion 4: potential for translation and effect on disease burden}

4.1. If the research question was answered, would the new knowledge be able to be used by other stakeholders in the current Australian primary healthcare system?

4.2. If the research question was answered, could the new knowledge facilitate improvements in healthy eating and/or physical activity behaviours of patients within a local context?

4.3. If the research question was answered, could the new knowledge support national improvements in primary healthcare service delivery?

4.4. If the research question was answered, is there potential to improve population healthy eating and/or physical activity behaviours by an amount that would cause a reduction in the burden of chronic disease at a population level? 
Table 1. Summary of scores for appraised research questions, in rank order of total score $(n=13)$

Research questions generated by stakeholder organisations

Criterion scores

Answerability (out of Sustainability Effectiveness

48)

(out of 24)

(out of 36)

Potential for translation and effect on disease burden (out of 48)
1. Would attending a weekly 10 -min health check at your local community pharmacy help improve patients' dietary

behaviours and level of physical activity?

2. To what extent does healthy literacy affect adherence to lifestyle behaviour change interventions?

3. What is the cost-benefit of various primary health professionals providing nutrition care and/or exercise care to patients?

4. What is the best way to improve dietary behaviours and physical activity levels in primary school children?

5. Which primary health professional is most effective at supporting improved dietary behaviours and physical activity levels?

6. How effective are 'walk to school groups' at reducing obesity and improving physical activity levels in children?

7. What factors influence long-term adherence to lifestyle interventions?

8. What is the best way to support increased physical activity levels in the primary healthcare setting?

9. To what extent do psychological interventions provided by various primary healthcare professionals support improvements in dietary behaviours?

10. Can primary health professionals facilitate long-term lifestyle changes in patients using online resources?

11. To what extent does physical activity lifestyle modification reduce the risk of developing a chronic disease?

12. What is the best way to support weight management in the primary healthcare setting?

13. What is the most effective diet on long-term weight management for primary care patients?
48

18

21

15

16

17

16
35

34

24

30

21
Total score

(out of 156)

Fig. 1. Overview of the stakeholder engagement process. 